\title{
Study of Ultrasonic and Pneumatic Nebulizers for ICP-MS Determination of Rare Earth Elements in Geological Samples
}

\author{
Frederico Garcia Pinto ${ }^{\text {a* }}$, Jairo Tronto ${ }^{a}$, Fábio Grandis Leprib ${ }^{b}$ Luciano Tormenc, Tatiana Dillenburg \\ Saint'Pierre ${ }^{\mathrm{d}}$, Letícia Malta Costa ${ }^{\mathrm{e}}$, Mark Antony Beinner ${ }^{\mathrm{f}}$, and José Bento Borba da Silva ${ }^{\mathrm{e}}$ \\ ${ }^{a}$ Department of Chemistry, Federal University of Viçosa, Rio Paranaíba, MG, Brazil \\ ${ }^{b}$ Department of Chemistry, Fluminense Federal University, Niterói, RJ, Brazil \\ c Department of Chemistry, Federal University of Fronteira Sul, Laranjeiras do Sul, PR, Brazil \\ d Department of Chemistry, Pontifical Catholic University of Rio de Janeiro, Rio de Janeiro, RJ, Brazil \\ e Department of Chemistry, Federal University of Minas Gerais, Belo Horizonte, MG, Brazil \\ ${ }^{f}$ School of Nursing and Nutrition, Federal University of Minas Gerais, Belo Horizonte, MG, Brazil
}

\section{INTRODUCTION}

Rare earth elements (REEs) have been increasingly employed in new technologies in industry (1-8). In environmental monitoring, these elements can be used as a geochemical fingerprint (9), as well as an indicator of anthropogenic sources (10) and, more recently, to fingerprint wine (11). Thus, the necessity of reliable methods for the separation and determination of REEs in geological samples has grown in recent years (12-20).

Inductively coupled plasma mass spectrometry (ICP-MS) is one of the most widely employed techniques for the determination of REEs in geological samples. These are commonly dissolved by means of microwave digestion since they require high energy and strong acid media for dissolution (21). In this case, the disadvantages of the standard and most common pneumatic nebulizer $(\mathrm{PN})$ for sample introduction become more important, since the amount of dissolved solids in the solutions must be limited. In addition, the nebulization efficiency is too low, resulting in limits of detection that can be too high for this purpose. To overcome these problems, alternative sample introduction accessories and sample preparation procedures may be

*Corresponding author.

E-mail: fredericogarcia.ufv@gmail.com

(F. G. Pinto)

Tel: $+55-34-3855-9015$

Fax: +55-34-3855-9317

\section{ABSTRACT}

In this work, pneumatic and ultrasonic nebulizers were studied for the determination of rare earth (REEs) and other elements in geological samples by inductively coupled plasma mass spectrometry. The optimum nebulizer gas flow rate was 1.05 and 1.10

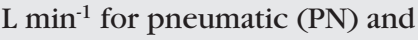
ultrasonic nebulization (USN), respectively, with an $\mathrm{RF}$ power of $1100 \mathrm{~W}$. Calibration curves were prepared with aqueous standards, using $10 \mu \mathrm{g} \mathrm{L}^{-1}$ of $\mathrm{Rh}$ as an internal standard, which was not mandatory when USN was employed.

Accuracy was checked through the analysis of four geological certified reference materials. Better detection power was obtained with the USN, whose LODs were between $0.01 \mathrm{ng} \mathrm{L}^{-1}$ for $\mathrm{U}$ and $1.4 \mathrm{ng} \mathrm{L}^{-1}$ for Ce, while those for PN were between $0.2 \mathrm{ng} \mathrm{L}^{-1}$ for $\mathrm{Lu}$ and $\mathrm{Tm}$, and $7.4 \mathrm{ng} \mathrm{L}^{-1}$ for Y. Both nebulizers allowed enough sensitivity to determine REEs in Brazilian rock samples.

required (22). For example, ultrasound-assisted extraction was proposed as sample pre-treatment for the quantitative determination of rare earth elements in marine biological tissues (23).

In order to improve the sensitivity of the technique, the ultrasonic nebulizer (USN) is very attractive because it provides better introduc- tion efficiency, minimizes interferences from volatile components of the sample solution (24-26), and improves the signal-to-background ratio (27). The coupling of a USN to the ICP-MS has been successfully employed in the analysis of geological samples, such as rocks, minerals and water (28-33). To minimize interferences, especially from oxides, a micro-concentric nebulizer, cooled spray chamber, and membrane desolvation system have been used to reduce the solvent load into the plasma $(34,35)$. Reaction cell and sector field instruments, optimized for the determination of REEs, resulted in improved performance, lower detection limits and lower interference levels when compared with standard quadrupole instruments (34-36).

In the present study, a simple method for the determination of REEs in geological samples by ICPMS is proposed. The introduction of acid-dissolved geological reference materials in the ICP-MS is carried out through pneumatic and ultrasonic nebulizers to compare their feasibility and performance. The experimental parameters, using both nebulizers, were optimized in order to determine REEs using calibration with aqueous standard solutions containing an internal standard. The developed method was validated by analyzing reference samples and employed to quantify REEs in rock samples from the southeastern state of Minas Gerais, Brazil. 


\section{EXPERIMENTAL}

\section{Instrumentation}

A PerkinElmer ${ }^{\circledR}$ ELAN ${ }^{\circledR} 6000$ (PerkinElmer, Inc., Shelton, CT, USA) inductively coupled plasma mass spectrometer with a crossflow pneumatic nebulizer and a Scott-type spray chamber or with an ultrasonic nebulizer CETAC U5000 AT (Omaha, Nebraska, USA) was used for the measurements. Argon of $99.996 \%$ purity (White Martins, São Paulo, Brazil) was used. The ICP-MS operating conditions are listed in Table I.

An MLS 1200 Mega (Milestone, Sorisole, Italy) microwave oven was used for sample digestion. The following isotopes were measured: ${ }^{140} \mathrm{Ce},{ }^{164} \mathrm{Dy},{ }^{166} \mathrm{Er},{ }^{153} \mathrm{Eu},{ }^{158} \mathrm{Gd},{ }^{165} \mathrm{Ho}$, ${ }^{139} \mathrm{La},{ }^{175} \mathrm{Lu},{ }^{142} \mathrm{Nd},{ }^{141} \mathrm{Pr},{ }^{152} \mathrm{Sm},{ }^{159} \mathrm{~Tb}$, ${ }^{232} \mathrm{Th},{ }^{169} \mathrm{Tm},{ }^{238} \mathrm{U},{ }^{89} \mathrm{Y}$, and ${ }^{174} \mathrm{Yb}$.

\section{Reagents}

All reagents were of analytical grade. The water (resistivity of $18.2 \mathrm{M} \Omega \mathrm{cm}$ ) was de-ionized in a Milli-Q ${ }^{\circledR}$ system (Millipore Corporation, Bedford, MA, USA). Nitric acid (Carlo Erba, Milan, Italy) and hydrofluoric acid (Merck, Darmstadt, Germany) were further purified by sub-boiling distillation in quartz and poly(tetrafluorethylene) stills, respectively (both from Kürner Analysentechnik, Rosenheim, Germany). Hydrogen peroxide $30 \%$ (v/v) (Merck, Darmstadt, Germany) was employed as an oxidizing agent in the sample preparation, and boric acid (Fluka, Switzerland) was used for the elimination of excess hydrofluoric acid (HF). A multielement plasma standard solution ICPMS-1 (Spex, Metuchen, NJ, USA), containing $10 \mathrm{mg} \mathrm{L}^{-1}$ of Ce, Dy, Er, $\mathrm{Eu}, \mathrm{Gd}, \mathrm{Ho}, \mathrm{La}, \mathrm{Lu}, \mathrm{Nd}, \mathrm{Pr}, \mathrm{Sm}, \mathrm{Tb}$, $\mathrm{Th}, \mathrm{Tm}, \mathrm{Y}$, and $\mathrm{Yb}$, was used for the preparation and calibration of the solutions. A mono-elemental standard solution, containing $10 \mathrm{mg} \mathrm{L}^{-1}$ of Rh (Spex, Metuchen, NJ, USA), was used for the internal standard.

\section{Samples}

The following reference materials were analyzed: LKSD-2 Lake Sediment and STSD-2 Stream Sediment, both from the Canadian Certified Reference Materials Project (CCRMP, Ottawa, Canada); SOIL-7 Soil Sample and WGB-1 Rock Sample, both from the International Atomic Energy Agency (IAEA, Vienna, Austria).

Twenty-one rock samples from different regions of the southeastern state of Minas Gerais, Brazil, were analyzed, following the proposed sample preparation and method.

\section{Sample Preparation}

The principal challenge related to geological sample analysis is sample preparation due to the refractory matrix components, such as silicates. Sample preparation procedures used to be time-consuming and employed complex conditions (21). In this study, completely dissolved samples were introduced into the ICP by nebulization. The samples were digested in a microwave oven, as described below, and a procedure for eliminating the use of HF was evaluated by applying it to the certified samples.

\section{Atomic Apectroscopy \\ $\bigcirc$ Vol. 36(3), May/June 2015}

The reference samples (as listed above) were obtained in powder form and directly weighed. The rock samples were first ground in a ball mill before being submitted to the selected dissolution process. The blanks were prepared following the same procedures as applied to the samples.

\section{Dissolution Process}

In the polytetrafluoroethylene (PTFE) oven vessels, an aliquot of approximately $100 \mathrm{mg}$ of the sample was weighed and mixed with $4.0 \mathrm{~mL}$ of $65 \%(\mathrm{~m} / \mathrm{v})$ nitric acid, $2.0 \mathrm{~mL}$ of $40 \%(\mathrm{~m} / \mathrm{v})$ hydrofluoric acid, and $2.0 \mathrm{~mL}$ of $30 \%(\mathrm{v} / \mathrm{v})$ hydrogen peroxide. The vessels were sealed and, in order to get better decomposition efficiency for all flasks since this microwave oven model has no temperature sensor, the mixtures were submitted twice to the following microwave oven program: 6 minutes at $250 \mathrm{~W}$, 6 minutes at $400 \mathrm{~W}, 6$ minutes at $650 \mathrm{~W}$, and 6 minutes at $250 \mathrm{~W}$.

Determination of the total concentration of the REEs in geological samples requires the use of hydrofluoric acid for their complete dissolution, since these elements can be associated with the silicate

TABLE I

ICP-MS Instrumental Conditions for the PN and USN Nebulizers

\begin{tabular}{|c|c|c|}
\hline & \multicolumn{2}{|c|}{ ICP-MS Conditions } \\
\hline Plasma gas flow rate & \multicolumn{2}{|c|}{$15 \mathrm{~L} \mathrm{~min}^{-1}$} \\
\hline Auxiliary gas flow rate & \multicolumn{2}{|c|}{$1.2 \mathrm{~L} \mathrm{~min}^{-1}$} \\
\hline Sampler and skimmer cones & \multicolumn{2}{|c|}{$\mathrm{Pt}$} \\
\hline Dwell time & \multicolumn{2}{|c|}{$25 \mathrm{~ms}$} \\
\hline Sweeps per reading & \multicolumn{2}{|c|}{30} \\
\hline Readings per replicate & \multicolumn{2}{|l|}{1} \\
\hline \multirow[t]{2}{*}{ Replicates } & \multicolumn{2}{|l|}{3} \\
\hline & $\mathrm{PN}$ & USN \\
\hline Nebulizer gas flow rate & \multirow{2}{*}{$\begin{array}{l}1.05 \mathrm{~L} \mathrm{~min}^{-1} \\
1100 \mathrm{~W}\end{array}$} & $1.10 \mathrm{~L} \mathrm{~min}^{-1}$ \\
\hline RF power & & $1100 \mathrm{~W}$ \\
\hline \multirow[t]{2}{*}{ Desolvation temperatures: } & & Heating $130{ }^{\circ} \mathrm{C}$ \\
\hline & & Cooling $-3^{\circ} \mathrm{C}$ \\
\hline
\end{tabular}


matrix. The dissolution of silicates is represented in equation 1 (37):

Eq. 1

$\mathrm{SiO}_{2}+6 \mathrm{HF} \rightarrow \mathrm{H}_{2} \mathrm{SiF}_{6}+2 \mathrm{H}_{2} \mathrm{O}$

The resulting solutions were not completely clear, presenting a fine white precipitate, and excess $\mathrm{HF}$ must be removed to avoid damage to the glass and quartz equipment parts. Therefore, after the decomposition in the microwave oven, two procedures for eliminating the use of HF were evaluated:

\section{Elimination of HF Excess}

In order to allow the introduction of the sample solutions into the plasma by means of the conventional introduction system, the excess of HF has to be eliminated. For that, two different procedures were compared:

\section{Procedure 1: Simple evaporation}

The hexafluorosilicic acid can be decomposed and excess HF removed by heating the solution in acid media:

Eq. 2

$\mathrm{H}_{2} \mathrm{SiF}_{6} \rightarrow \mathrm{SiF}_{4(\mathrm{~g})}+2 \mathrm{HF}_{(\mathrm{g})}$

The PTFE vessels of the microwave oven were transferred to a hot plate and the mixtures heated at $80^{\circ} \mathrm{C}$ until near dryness; then the residues were transferred to polyethylene flasks and diluted with a $1 \%$ (v/v) nitric acid solution to a $50-\mathrm{mL}$ final volume.

\section{Procedure 2: Reaction with boric acid and beating}

Excess HF can be removed by reaction with boric acid according to the following reaction:

Eq. 3

$\mathrm{H}_{3} \mathrm{BO}_{3}+3 \mathrm{HF} \rightarrow \mathrm{HBF}_{3}(\mathrm{OH})+2 \mathrm{H}_{2} \mathrm{O}$

$\mathrm{HBF}_{3}(\mathrm{OH})+\mathrm{HF} \rightarrow \mathrm{HBF}_{4}+\mathrm{H}_{2} \mathrm{O}$

After the microwave oven program, the PTFE flasks were transferred to a hot plate, followed by the addition of $1 \mathrm{~g}$ of boric acid, and heated for 1 hour at $80^{\circ} \mathrm{C}$. The resulting solutions were transferred to polyethylene flasks and diluted with a $1 \%(v / v)$ nitric acid solution to a $50-\mathrm{mL}$ final volume. Additionally, the solution was diluted 10 times and $10 \mu \mathrm{g} \mathrm{L}^{-1}$ of rhodium was added to the final concentration. The internal standard was added to all calibration solutions, samples and blanks, and then analyzed with the PN and USN nebulizers.

\section{RESULTS AND DISCUSSION}

\section{Evaluation of Sample Prepara- tion}

The elimination of excess HF can be performed efficiently by simple evaporation. However, it did not prove sufficient for complete dissolution of the studied samples. Hydrofluoric acid, fundamental for silicate dissolution, forms slightly soluble fluorides during sample digestion in the microwave oven. The fluoride anion is a strong complexing agent, forming precipitates with REEs present in high concentrations or co-precipitating REEs with $\mathrm{Ca}$ (II) and $\mathrm{Mg}$ (II) fluorides present in mineral samples (38-39). Solubilities of some REE fluorides (in $\mathrm{mol} \mathrm{L}^{-1}$, at $25^{\circ} \mathrm{C}$ ) are listed in Table II.

Simple heating of the solutions proved insufficient since the recoveries of some analytes were low and gave poor precision, suggesting that even when the solutions appear clear, very fine precipitates remain in the solution.

To solve this problem, boric acid was added to the HF elimination step. It has been suggested (37) that anion tetrafluorborate $\left(\mathrm{BF}_{4}^{-}\right)$, formed by a boric acid reaction with a fluoride anion (Eq. 3), is stable enough to favor dissolution of slightly soluble REE fluorides. This affirmation was observed by the analysis of the signal intensities, measured by ICP-MS with the PN and using the certified sample LKSD-2, submitted to both sample preparation procedures. As shown in Figure 1, higher signal intensities are produced with procedure 2 when boric acid and heating was employed, compared with simple heating (procedure 1).

\section{Optimization of Instrumental Parameters}

\section{Pneumatic Nebulization}

The nebulizer gas flow rate optimization, presented in Figure 2, was carried out for a standard solution containing $10 \mu \mathrm{g} \mathrm{L}^{-1}$ of each analyte (2A) and for the LKSD-2 sample solution (2B). The behavior of the analytes was similar in both solutions: the signal intensities increasing to a maximum of 1.05 and $1.10 \mathrm{~L} \mathrm{~min}^{-1}$ for the standard and sample solutions, respectively. For higher nebulizer gas flow rates, the analyte intensities decreased quickly and similarly for both solutions. It has been reported (40) that higher gas flow rates change the sampling zone to colder regions in

\section{TABLE II}

Solubilities of Some REE Fluorides (47)

\begin{tabular}{cc}
\hline $\begin{array}{c}\mathrm{REE} \\
\text { Fluorides }\end{array}$ & $\begin{array}{c}\text { Solubilities } \\
\left.\text { (in } \mathrm{L}^{-1}, \text { at } 25^{\circ} \mathrm{C}\right)\end{array}$ \\
\hline $\mathrm{LaF}_{3}$ & $1.19 \times 10^{-19}$ \\
$\mathrm{CeF}_{3}$ & $5.58 \times 10^{-20}$ \\
$\mathrm{PrF}_{3}$ & $1.09 \times 10^{-19}$ \\
$\mathrm{NdF}_{3}$ & $2.36 \times 10^{-15}$ \\
$\mathrm{SmF}_{3}$ & $1.01 \times 10^{-18}$ \\
$\mathrm{EuF}_{3}$ & $5.98 \times 10^{-18}$ \\
$\mathrm{GdF}_{3}$ & $1.58 \times 10^{-17}$ \\
$\mathrm{TbF}_{3}$ & $1.85 \times 10^{-17}$ \\
$\mathrm{DyF}_{3}$ & $4.67 \times 10^{-17}$ \\
$\mathrm{HoF}_{3}$ & $1.33 \times 10^{-16}$ \\
$\mathrm{ErF}_{3}$ & $2.96 \times 10^{-16}$ \\
$\mathrm{TmF}_{3}$ & $1.50 \times 10^{-16}$ \\
$\mathrm{YbF}_{3}$ & $9.62 \times 10^{-16}$ \\
$\mathrm{LuF}_{3}$ & $8.42 \times 10^{-16}$ \\
\hline
\end{tabular}




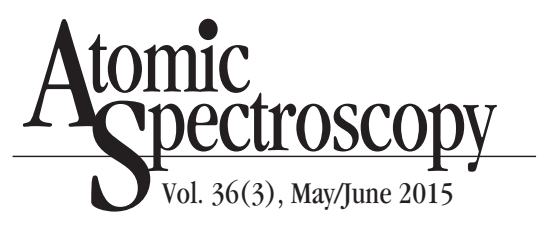

the plasma, where oxide formation occurs. The lower difference obtained in the maximum for standard and sample solutions is attributed to a higher amount of dissolved solids in the sample solution, resulting in higher viscosity, and consequently, requiring a higher gas flow rate. This behavior is important since the optimum

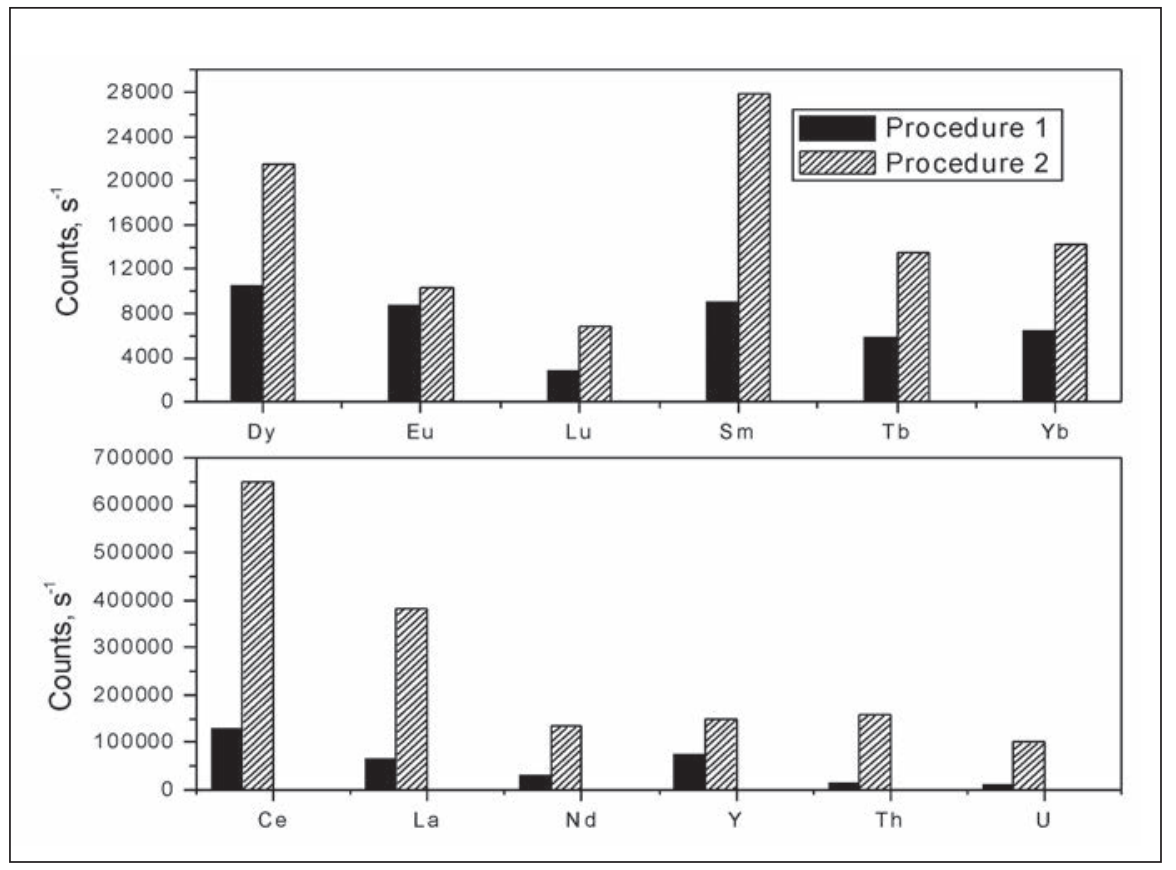

Fig. 1. Signal intensities obtained with PN ICP-MS for the REEs in LKSD-2 sample solution after microwave oven decomposition and employing procedure 1 or procedure 2 for excess HF elimination.

range is very narrow and small variations in the gas flow rate promote significant changes in analyte intensities. A compromise gas flow rate of $1.05 \mathrm{~L} \mathrm{~min}^{-1}$ was adopted for further experiments.

The RF power optimization is shown in Figure 3. In the standard solution (3A and 3B), most analytes have increasing intensities up to a maximum of $900 \mathrm{~W}$ (Eu, Er, Dy, Lu, $\mathrm{Ho}, \mathrm{Gd}, \mathrm{Tb}, \mathrm{Sm}, \mathrm{Tm}$, and $\mathrm{Yb}$ ) or up to $1000 \mathrm{~W}$ (Th and $\mathrm{U}$ ), while for elements with high ionization potential, such as $\mathrm{La}\left(799 \mathrm{~kJ} \mathrm{~mol}^{-1}\right)$ and $\mathrm{Ce}\left(795 \mathrm{~kJ} \mathrm{~mol}^{-1}\right)$, and also $\mathrm{Pr}$, $\mathrm{Nd}$, and $\mathrm{Y}$, which require higher energy for ionization, the sensitivity increases up to a higher RF power. For the LKSD-2 sample solution (3C), the intensities of the analytes increased with increasing RF power across the studied ranges. This behavior was expected, since the sample solution requires more energy for dissociation of the dissolved salts from the matrix than the standard solution. In order to guarantee maximum analyte ionization in the sample without significant sensitivity loss of the analytes in the calibration standard solutions,
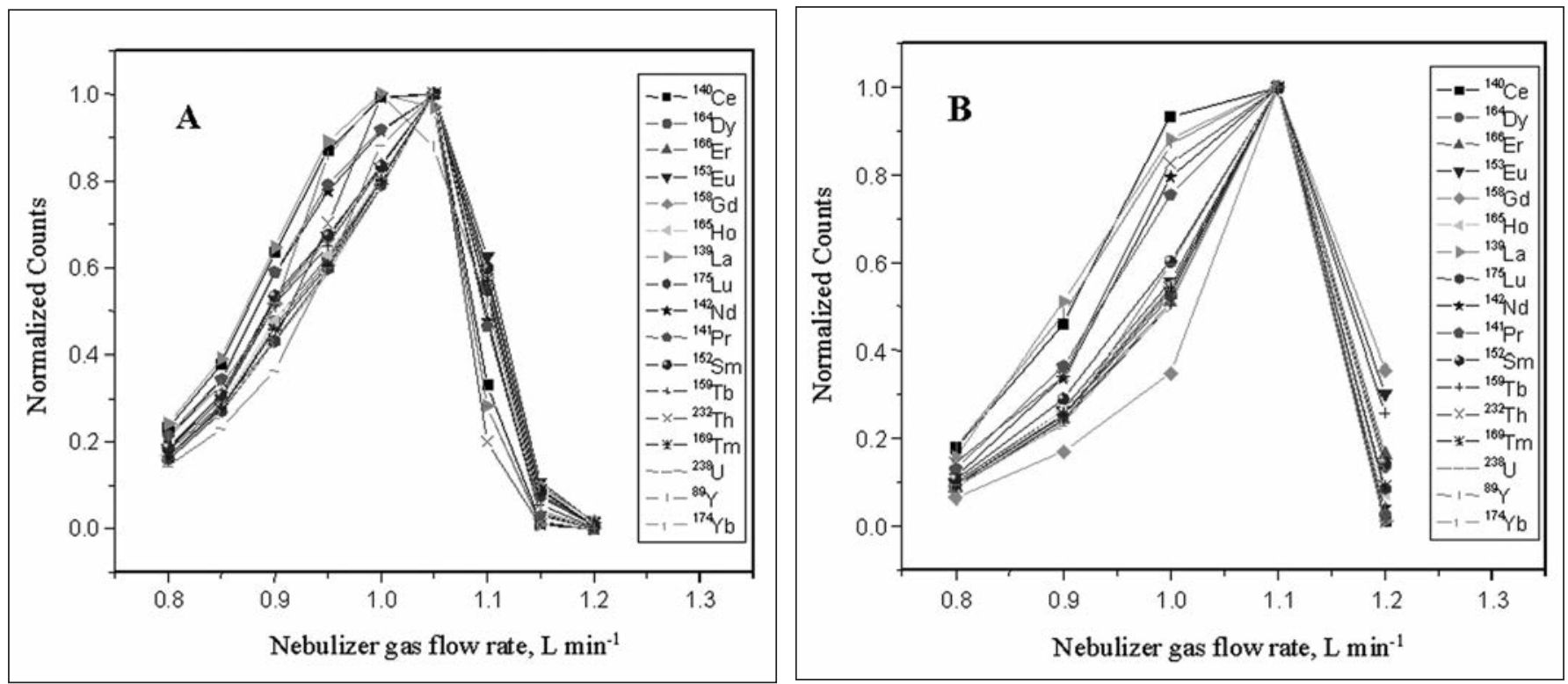

Fig. 2 (AEB). Pneumatic nebulizer gas flow rate optimization for the REE in (A) $10 \mu g L^{-1}$ aqueous standard solution and (B) LKSD-2 sample solution. RF power: $1000 \mathrm{~W}$. 

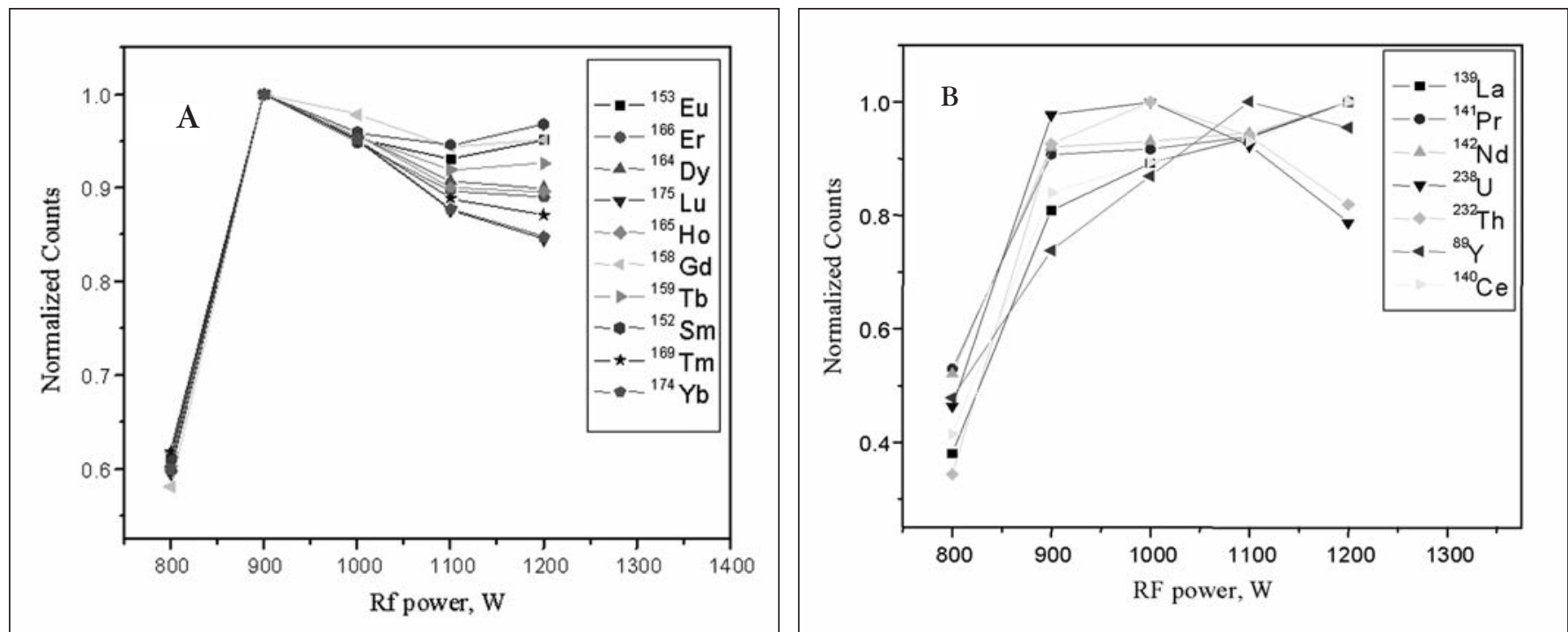

Fig. $3\left(A, B, C\right.$ ). RF power optimization for the REE in (A and B) $10 \mu g L^{-1}$ aqueous standard solution, and $(C)$ LKSD-2 sample solution, applying the PN. Optimized gas flow rate: $1.05 \mathrm{~L} \mathrm{~min}^{-1}$.

a compromise of $1100 \mathrm{~W}$ RF power was selected for the analysis.

\section{Ultrasonic Nebulization}

Initially, the plasma operational parameters were kept within the conditions recommended by the ultrasonic nebulizer manual $(0.7 \mathrm{~L}$ $\mathrm{min}^{-1}$ gas flow rate and $1200 \mathrm{~W} \mathrm{RF}$ power). The USN desolvation system temperatures were optimized and the selected temperatures were $130{ }^{\circ} \mathrm{C}$ and $-3{ }^{\circ} \mathrm{C}$ for vaporization and condensation, respectively.
The solution flow rate was adjusted to $2.4 \mathrm{~mL} \mathrm{~min}^{-1}$ as recommended by the manufacturer.

Under these conditions, the gas flow rate was optimized for the standard solution containing $10 \mu \mathrm{g}$ $\mathrm{L}^{-1}$ of analytes (Figure $4 \mathrm{~A}$ ) and the LKSD-2 sample solution (Figures 4B and $4 \mathrm{C})$. In examining the standard solution graph (4A), all analytes behave similarly: the signal intensities increase to a maximum at $\mathbf{1 . 1 0}$ $\mathrm{L} \min ^{-1}$ and then decrease quickly.
The effect of the gas flow rate on the analyte intensity in the sample solution was not the same for all elements. For most of them, the resulting curves were similar to those for the standard solution, with a maximum of 1.10 or $1.20 \mathrm{~L} \mathrm{~min}^{-1}$. For $\mathrm{Eu}(4 \mathrm{~B})$ and $\mathrm{Tb}$ (4C), the curves stabilize for flow rates higher than $1.20 \mathrm{~L} \mathrm{~min}^{-1}$, and for $\mathrm{Gd}(4 \mathrm{C})$, the curve was continually upwards in the studied range. Higher gas flow rates provide a favorable environment for the formation of oxides in the plasma. In fact, the stabilization for ${ }^{153} \mathrm{Eu}$ may be attributed to the formation of interfering ${ }^{137} \mathrm{Ba}^{16} \mathrm{O}^{+}$at higher flow rates, since $\mathrm{Ba}$ is present in a relatively higher concentration in this sample (780 $\mathrm{g} \mathrm{g} \mathrm{g}^{-1}$ as the informed concentration), and not present in the standard solution. In the example of ${ }^{158} \mathrm{Gd}$ and ${ }^{159} \mathrm{~Tb}$, the interference may be due to the formation of ${ }^{142} \mathrm{Nd}^{16} \mathrm{O}^{+}$or ${ }^{142} \mathrm{Ce}^{16} \mathrm{O}^{+}$and ${ }^{143} \mathrm{Nd}^{16} \mathrm{O}^{+}$, respectively, as verified by reduction of the intensities of these elements with higher gas flow rates. The spectral interferences from lower REEs compared to higher REEs have been previously reported (13-22). A compromise condition of $1.10 \mathrm{~L} \mathrm{~min}^{-1}$ gas flow rate was adopted for further experiments. 


\section{Atomic Spectroscopy \\ Vol. 36(3), May/June 2015}
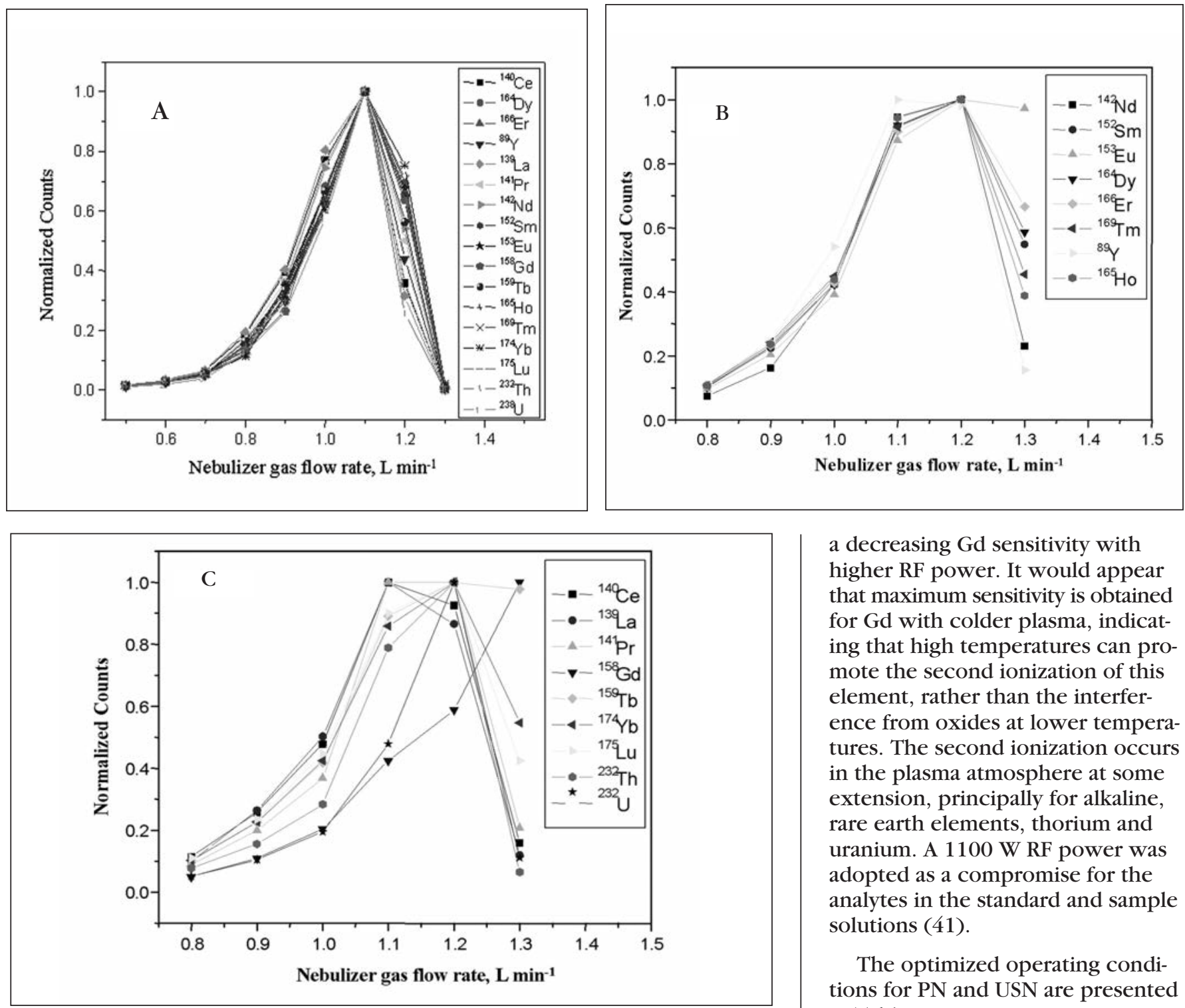

Fig. 4 (A,B,C). Ultrasonic gas flow rate optimization for the REE in (A) $10 \mu g L^{-1}$ aqueous standard solution and $(B$ and $C$ ) LKSD-2 sample solution. RF power: $1200 \mathrm{~W}$.

The RF power was also investigated for standard (Figure 5A) and sample solutions (Figure 5B). Once again, a similar behavior was observed for the standard solution analytes, increasing the sensitivities with a higher RF power: a maximum of $1100 \mathrm{~W}$ for most analytes, and up to $1300 \mathrm{~W}$ for Ce, La, Nd, Pr, Th, U, and Y, and then the intensity stabilizes or slowly decreases. For the sample solution, maximum sensitivity was obtained with $1000 \mathrm{~W}$ for most analytes, with the exception of ${ }^{158} \mathrm{Gd}$ and ${ }^{238} \mathrm{U}$. For $\mathrm{U}$, the behavior was similar to the other analytes, but maximum was obtained with $900 \mathrm{~W}$ RF power, although the sensitivity was still high at $1000 \mathrm{~W}$. The results for $\mathrm{Gd}$ were quite interesting. We observed a different behavior, namely, a decreasing Gd sensitivity with higher RF power. It would appear that maximum sensitivity is obtained for Gd with colder plasma, indicating that high temperatures can promote the second ionization of this element, rather than the interference from oxides at lower temperatures. The second ionization occurs in the plasma atmosphere at some extension, principally for alkaline, rare earth elements, thorium and uranium. A $1100 \mathrm{~W}$ RF power was adopted as a compromise for the analytes in the standard and sample solutions (41).

The optimized operating conditions for PN and USN are presented in Table I.

\section{Figures of Merit}

The limits of detection (LODs) were calculated as three times the standard deviation of 10 measurements of the blank solution divided by the slope of the calibration curve. The calibration curves were carried out with solutions containing between 5 and $170 \mu \mathrm{g} \mathrm{L}^{-1}$ of each analyte and $10 \mu \mathrm{g} \mathrm{L}^{-1}$ of ${ }^{103} \mathrm{Rh}$, used as the internal standard. The correlation coefficients of the calibration curves were greater than 0.999 for all of the studied analytes, 

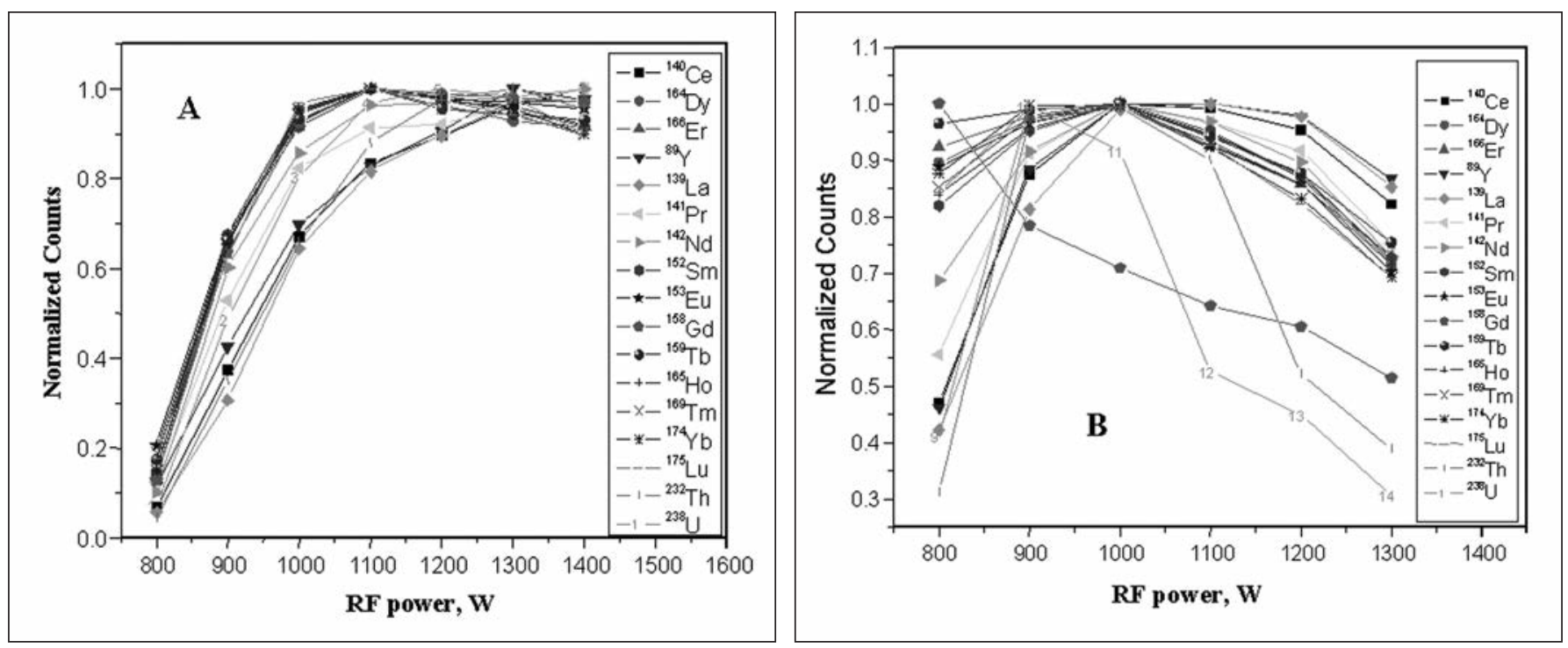

Fig. 5 (A and B). RF power optimization for the REE in (A) $10 \mu g L^{-1}$ aqueous standard solution and (B) LKSD-2 sample solution, applying the USN. Optimized gas flow rate: $1.10 \mathrm{~L} \mathrm{~min}^{-1}$.

employing pneumatic nebulization or ultrasonic nebulization. The LODs in the sample solution were between 0.20 and $7.40 \mathrm{ng} \mathrm{L}^{-1}$ with pneumatic nebulization, and between 0.01 and $1.35 \mathrm{ng} \mathrm{L}^{-1}$ with ultrasonic nebulization. Therefore, in the sample, this corresponded to 1.00 and $37.00 \mathrm{ng} \mathrm{g}^{-1}$ for PN and 0.07 and $6.75 \mathrm{ng} \mathrm{g}^{-1}$ for USN. The precision, expressed as the RSD of 5 concentration measurements for each analyte in the LKSD-2 sample, was greater than $10 \%$ for both nebulizers. The LODs and precision, expressed as the relative standard deviation, are presented in Table III.

\section{Method Validation}

The accuracy of the proposed method was verified by analyzing four certified reference materials, employing PN and USN nebulizers. The necessity of using an internal standard to correct for the plasma fluctuations and different transport rates for sample and calibration solutions is well known (42) and is presented in Figures 6 and 7 . A $10 \mu \mathrm{g} \mathrm{L}^{-1} \mathrm{Rh}$ was employed because of its availability, although elements with higher mass and first ionization energy closer to REEs,
TABLE III

Figures of Merit

\begin{tabular}{|c|c|c|c|c|c|c|}
\hline \multicolumn{4}{|c|}{ PN } & \multicolumn{3}{|c|}{ USN } \\
\hline & $\begin{array}{c}\mathrm{LOD}^{\mathrm{a}} \\
\left(\mathrm{ng} \mathrm{g}^{-1}\right)\end{array}$ & $\begin{array}{c}\mathrm{LOD}^{\mathrm{b}} \\
\left(\mathrm{ng} \mathrm{g}^{-1}\right)\end{array}$ & $\begin{array}{l}\text { RSD } \\
(\%)\end{array}$ & $\begin{array}{c}\mathrm{LOD}^{\mathrm{a}} \\
\left(\mathrm{ng} \mathrm{g}^{-1}\right)\end{array}$ & $\begin{array}{c}\mathrm{LOD}^{\mathrm{b}} \\
\left(\mathrm{ng} \mathrm{g}^{1}\right)\end{array}$ & $\begin{array}{l}\text { RSD } \\
(\%)\end{array}$ \\
\hline $\mathrm{Ce}$ & 4.00 & 20.00 & 0.30 & 1.35 & 6.75 & 4.70 \\
\hline Dy & 0.80 & 4.00 & 0.50 & 0.07 & 0.36 & 2.40 \\
\hline Er & 0.40 & 2.00 & 1.10 & 0.03 & 0.17 & 4.00 \\
\hline $\mathrm{Eu}$ & 0.60 & 3.00 & 0.50 & 0.03 & 0.16 & 6.00 \\
\hline Gd & 1.20 & 6.00 & 0.90 & 0.23 & 1.13 & 4.00 \\
\hline Ho & 0.60 & 3.00 & 0.60 & 0.02 & 0.12 & 3.20 \\
\hline La & 1.60 & 8.00 & 0.40 & 0.05 & 0.22 & 1.60 \\
\hline $\mathrm{Lu}$ & 0.20 & 1.00 & 0.50 & 0.02 & 0.08 & 2.80 \\
\hline $\mathrm{Nd}$ & 6.00 & 30.00 & 0.30 & 0.62 & 3.11 & 3.30 \\
\hline $\operatorname{Pr}$ & 1.00 & 5.00 & 0.50 & 0.08 & 0.38 & 2.90 \\
\hline $\mathrm{Sm}$ & 1.60 & 8.00 & 0.90 & 0.08 & 0.40 & 2.80 \\
\hline $\mathrm{Tb}$ & 2.40 & 12.00 & 1.30 & 0.03 & 0.14 & 3.60 \\
\hline Th & 1.00 & 5.00 & 0.90 & 0.05 & 0.25 & 4.10 \\
\hline $\mathrm{Tm}$ & 0.20 & 1.00 & 2.10 & 0.02 & 0.11 & 3.50 \\
\hline $\mathrm{U}$ & 0.80 & 4.00 & 0.20 & 0.01 & 0.07 & 2.80 \\
\hline $\mathrm{Y}$ & 7.40 & 37.00 & 0.30 & 0.02 & 0.10 & 6.50 \\
\hline $\mathrm{Yb}$ & 0.80 & 4.00 & 0.40 & 0.07 & 0.36 & 7.00 \\
\hline
\end{tabular}

${ }^{a}$ In the sample solution. 
such as In $(13,43,44)$ or $\mathrm{Tl}(45)$, could also be employed.

As expected, without an internal standard and using the PN (Figure $6)$, the measured concentrations were lower than the certified or informed (non-certified) values for most analytes. Besides the differences in nebulization and transport between samples and calibration solutions by PN, this behavior may also be attributed to signal suppression due to the presence of high alkaline concentrations in the samples (44). Poorest results were obtained without internal standard for the WGB-1 sample; that is, the one with higher concentrations of alkaline and earth alkaline elements. However, the SOIL-7 sample, which has lower concentrations of these elements, demonstrated better results, with some REE measured concentrations in agreement with the certified values.

For some elements, competition between opposite effects of different interferences is expected, i.e., signal suppression due to alkalines and positive oxide isobaric interference, such as ${ }^{137} \mathrm{Ba}^{16} \mathrm{O}^{+}$over ${ }^{153} \mathrm{Eu}^{+}$ and ${ }^{159} \mathrm{~Tb}^{16} \mathrm{O}^{+}$over ${ }^{175} \mathrm{Lu}^{+}$.

Using the USN, the measured concentrations are in agreement with the reference values, even without the internal standard, since this nebulizer promotes higher nebulization efficiency and a more stable aerosol, minimizing fluctuation. In addition, the desolvator system allows elimination of part of the solvent and volatile components of the sample matrix, reducing interference (41). As observed in Figure 7 , in general, the internal standard improved the result accuracy also with the USN, due to the correction of fluctuations in the transport solutions. However, a longer analysis time and worse precision were observed for the USN, which was attributed to the memory effect common to this nebulizer.
Figures 6 and 7 also show that the concentration results for REEs in the geological samples, using PN and USN with Rh as the internal standard, were in agreement with the certified values, according to the Student's $t$-test at a 95\% confidence level for most analytes, except for Th and $\mathrm{U}$ in some samples. Since these elements are not lanthanides, but actinides with much heavier masses, their behavior in the plasma is different and could not be corrected with Rh as the internal standardization. Using a combination of internal standards, according to masses and ionization energies, may have resulted in better accuracy. However, this possibility was not tested.

\section{Analytical Application}

Twenty-one rock samples from the southeastern state region of Minas Gerais (Brazil) were analyzed following the proposed methodology, employing a pneumatic nebulizer, since this method presented some advantages including simplicity, fast results, and lower cost, although both nebulizers provided sensitivity enough to allow for the accurate determination of REEs in rock samples. The resulting concentration ranges of most analyzed samples, presented in Table IV, were in the same order of magnitude of other rock samples from different parts of Brazil, based on the results reported by Nardy et al. (46) employing ICP-OES. Comparing our results with these authors, almost all the studied analytes (except Th) had coincidental concentration ranges, demonstrating a trend in the concentration levels of REEs in Brazilian rocks. An exception was found for sample 21, which presented much higher concentrations of some REEs, principally Ce (1.97 $\left.\mathrm{mg} \mathrm{g}^{-1}\right), \mathrm{La}(142.50$ $\left.\mu \mathrm{g} \mathrm{g}^{-1}\right)$, Nd (98.17 $\left.\mu \mathrm{g} \mathrm{g}^{-1}\right)$, and Th (97.40 $\left.\mu \mathrm{g} \mathrm{g}^{-1}\right)$.

\section{Atomic Spectroscopy 1 Vol. 36(3), May/June 2015}

In general, the REEs could be divided in two groups in the analyzed Brazilian rocks: those with low concentrations $\left(<22.4 \mu \mathrm{g} \mathrm{g}^{-1}\right)$ : $\mathrm{Pr}, \mathrm{Sm}, \mathrm{Dy}, \mathrm{Eu}, \mathrm{Tb}, \mathrm{Ho}, \mathrm{Gd}, \mathrm{Er}, \mathrm{Tm}$, $\mathrm{Yb}$, and $\mathrm{Lu}$, and the group with high concentrations (> $52.7 \mu \mathrm{g} \mathrm{g}^{-1}$ ): $\mathrm{Y}, \mathrm{La}, \mathrm{Ce}, \mathrm{Nd}, \mathrm{Th}$, and $\mathrm{U}$. Of course, more specific geological studies and a larger sample size are recommended for analysis and better characterization and classification of the samples.

\section{CONCLUSION}

The results of this study show that pneumatic nebulization (PN) or ultrasonic nebulization (USN) can be employed in the determination of REEs in geological samples by inductively coupled plasma mass spectrometry (ICP-MS), after sample acid digestion. Optimization of the instrumental parameters was made possible by calibration using aqueous standard solutions with $\mathrm{Rh}$ as an internal standard. Better detection capability and nebulization efficiency were obtained using USN, and the LODs were from 3 (Ce) to 370 (Y) times lower than with PN. However, longer analysis time and poorer precision were observed with this USN. The PN demonstrated good performance, and the internal standard was mandatory for this nebulizer, which also demonstrated enough sensitivity for the analyzed samples.

The method described in this paper was applied to the determination of REEs in rock samples from Brazilian soil. It was possible to identify that the analytes $\mathrm{Pr}, \mathrm{Sm}$, Dy, Eu, Tb, Ho, Gd, Er, Tm, Yb, and Lu formed a group of elements that presented the lowest concentration values $\left(<22.40 \mathrm{~g} \mathrm{~g}^{-1}\right)$, and another group, $\mathrm{Y}, \mathrm{La}, \mathrm{Ce}, \mathrm{Nd}$, Th, and $\mathrm{U}$, which presented the highest values $\left(>52.67 \mathrm{~g} \mathrm{~g}^{-1}\right.$ ). 

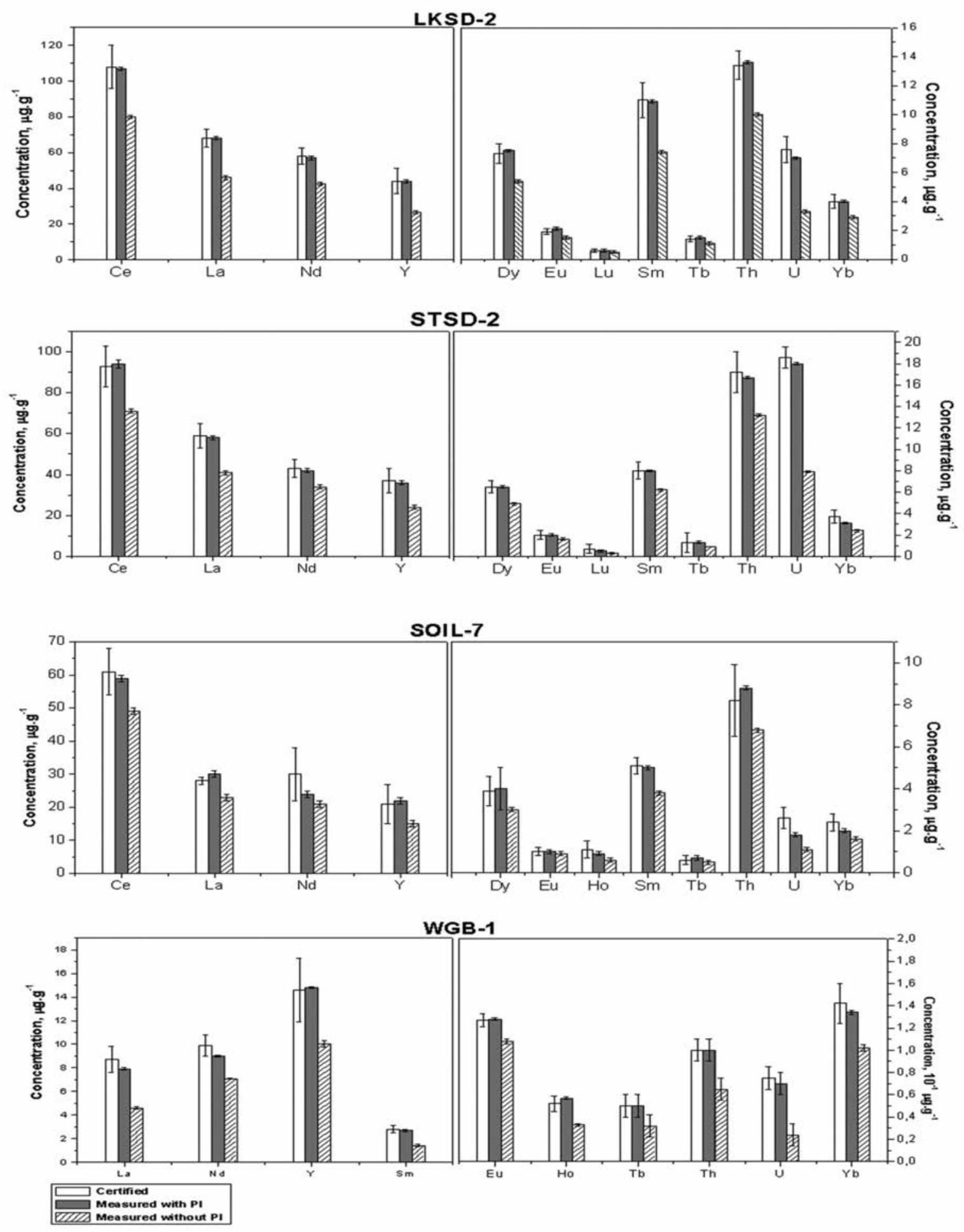

Fig. 6. Certified or informed by the manufacturer and measured values with and without $10 \mu g L^{-1}$ of Rh as internal standard (PI) $(n=5,95 \%)$ for REEs, $U$, Th and Y in LKSD-2, SOIL-7, STSD-2, and WGB-1 reference materials with sample introduction in the ICP by pneumatic nebulizer, external calibration with standard solutions using $1100 \mathrm{~W}$ RF power, and a $1.1 \mathrm{~L} \mathrm{~min}^{-1}$ nebulizer gas flow rate. 


\section{Atomic Spectroscopy \\ 1 Vol. 36(3), May/June 2015}

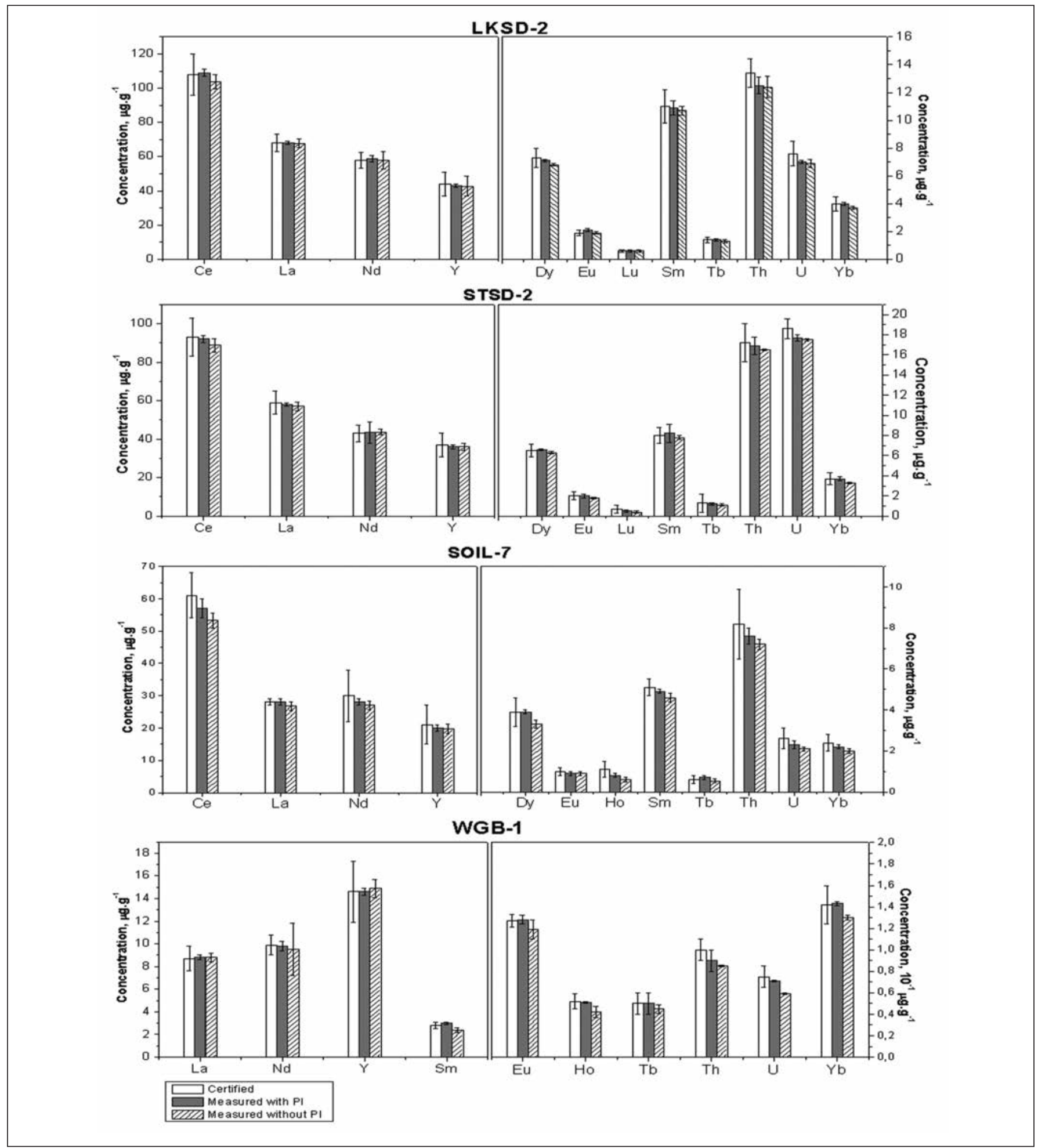

Fig. 7. Certified or informed by the manufacturer and measured values with and without $10 \mu g L^{-1}$ of Rh as internal standard (PI) ( $n=5,95 \%)$ for REEs, $U$, Th, and Y in LKSD-2, SOIL-7, STSD-2, and WGB-1 reference materials with sample introduction in the ICP by ultrasonic nebulizer, external calibration with standard solutions using $1100 \mathrm{~W}$ RF power, and a $1.1 \mathrm{~L}^{\mathrm{min}}{ }^{-1}$ nebulizer gas flow rate. 
TABLE IV

Concentration Ranges ( $\mu \mathrm{g} \mathrm{g}^{-1}$ ) for REE, Th, $\mathrm{U}$, and $\mathrm{Y}$ in 21 Brazilian Rock Samples (n=3) Determined by PN-ICP-MS

\begin{tabular}{cll}
\hline & \multicolumn{2}{c}{ Concentration range $\left(\mu \mathrm{g} \mathrm{g}^{-1}\right)$} \\
Analyte & Lower Value & $1966.600 \pm 98.330$ \\
$\mathrm{Ce}$ & $1.600 \pm 0.080$ & $12.500 \pm 0.625$ \\
$\mathrm{Dy}$ & $0.100 \pm 0.005$ & $7.100 \pm 0.355$ \\
$\mathrm{Er}$ & $0.080 \pm 0.004$ & $6.000 \pm 0.300$ \\
$\mathrm{Eu}$ & $0.400 \pm 0.020$ & $22.400 \pm 1.120$ \\
$\mathrm{Gd}$ & $0.100 \pm 0.005$ & $2.500 \pm 0.125$ \\
$\mathrm{Ho}$ & $0.030 \pm 0.002$ & $142.500 \pm 7.125$ \\
$\mathrm{La}$ & $0.900 \pm 0.045$ & $1.070 \pm 0.054$ \\
$\mathrm{Lu}$ & $0.010 \pm 0.001$ & $98.200 \pm 4.910$ \\
$\mathrm{Nd}$ & $0.600 \pm 0.003$ & $21.000 \pm 1.050$ \\
$\mathrm{Pr}$ & $0.200 \pm 0.010$ & $13.900 \pm 0.695$ \\
$\mathrm{Sm}$ & $0.900 \pm 0.046$ & $2.100 \pm 0.105$ \\
$\mathrm{~Tb}$ & $0.020 \pm 0.001$ & $97.400 \pm 4.870$ \\
$\mathrm{Th}$ & $0.200 \pm 0.001$ & $1.000 \pm 0.050$ \\
$\mathrm{Tm}$ & $0.010 \pm 0.001$ & $52.670 \pm 2.634$ \\
$\mathrm{U}$ & $0.500 \pm 0.025$ & $69.600 \pm 3.480$ \\
$\mathrm{Y}$ & $2.800 \pm 0.140$ & $6.600 \pm 0.330$ \\
$\mathrm{Yb}$ & $0.200 \pm 0.010$ &
\end{tabular}

\section{ACKNOWLEDGMENT}

The authors wish to thank the Conselho Nacional de Pesquisas e Desenvolvimento Tecnológico (CNPq). We thank the CNPq, Brazil, for fellowships to J.B.B. Silva, L.M. Costa, and T.D. Saint'Pierre, and FAPERJ for the financial support and T.D. Saint'Pierre for the fellowship.

$\overline{\text { Received October 31, } 2014 .}$
8. M. He, B. Hu, and Z. C. Jiang, Anal. Chim. Acta 530, 105 (2005).

9. P. Henderson, Rare earth element geochemistry. Amsterdam, Netherlands: Elsevier, 1984.

10. Y. Suzuki, T. Suzuki, and N. Furuta, Anal. Sci. 26, 929 (2010).

11. S; Augagneur, B. Medina, J. Szpunar, and R. Lobinski, J. Anal. At. Spectrom. 11, 713 (1996).

12. K. E. Jarvis, J. Anal. At. Spectrom. 4, 563 (1989).

13. M. Totland, I. Jarvis, and K. E. Jarvis. Chem. Geol. 95, 35 (1992).

14. J. S. Alvarado, T. J. Neal, L. L. Smith, and M. D. Erickson, Anal. Chim. Acta 322, 11 (1996).

15. V. Balaram, Trends Anal. Chem. 15, 475 (1996).

16. J. L. de Boer, W. Verweij, T. van der Velde-Koerts, and W. Mennes, Wat. Res. 30, 190 (1996).

17. J. G. S. Gupta and N B. Bertrand, Talanta 42, 1595 (1996).

18. I. Jarvis, M. Totland, K. E. Jarvis, Chem. Geol. 143, 27 (1997).

19. K. J. M. Kramer, E. P. M. de Haan, H. Groenewoud, W. Dorten, G. N. Kramer, H. Muntau, and P. Quevauviller, Trends Anal. Chem. 21, 762 (2002).

20. S. V. Panteeva, D. P. Gladkochoub, T. V. Donskaya, V. V. Markova, and G. P. Sandimirova, Spectrochim. Acta Part B 58, 341 (2003).

21. S. Joannon, P. Telouk, and C. Pin, Spectrochim. Acta Part B 52, 1783 (1997).

22. K. Shinotsuka and M. Ebihara, Anal. Chim. Acta 338, 237 (1997).

23. M. Costas, I. Lavilla, S. Gil, F. Pena, I. de la Calle, N. Cabaleiro, C. Bendicho, Anal. Chim. Acta. 679, 49 (2010).

5. A. C. Jones, H. C. Aspinall, R. R. Chalker, R. J. Potter, K. Kukli, A. Rahtu, M. Ritala, and M. Leskela, Mat. Sci. Eng. B 118, 97 (2005).

6. R. A. Cutler, D. L. Meixner, B. T. Henderson, K. N. Hutchings, D. M. Taylor, and M, A. Wilson, Solid State Ionics 176, 2589 (2005).

7. C. X. Wang, W. Zhu, A. Peng, and R. Guichreit, Environ. Intern. 26, 309 (2001).
24. I. B. Brenner, A. Zander, M. Plantz, and J. Zhu, J. Anal. At. Spectrom. 12, 273 (1997).

25. S. H. Ke, L. S. Huang, S. J. Huang, and K. C. Lin, Applied Spectrosc. 55, 604 (2001).

26. M. Krachler, C. Mohl, H. Emons, and W. Shotyk, J. Anal. At. Spectrom. 17, 844 (2002). 
27. J. E. Carr, K. Kwok, G. K. Webster, and J. W. Carnahan, J. Pharm. Biomed. Anal. 40, 42 (2006).

28. J. C. Ely, C. R. Neal, J. A. O'Neill, Jr., and J. C. Jain, Chem. Geol. 157, 219 (1999)

29. T. F. Kraemer, M. W. Doughten, and T. D. Bullen, Environ. Sci. Technol. 36, 4899 (2002).

30. J. C. Jain, M. P. Field, C. R. Neal, J. C. Ely, and R. M. Sherrell, J. Geost. Geoanal. 24, 65 (2000).

31. W. R. Pedreira, J. E. S. Sarkis, C. A. S .Queiroz, C. Rodrigues, I. A. Tomiyoshi, and A. Abrão, J. Solid State Chem. 171, 3 (2003).

32. W. R. Pedreira, C. A. S. Queiroz, A. Abrão, and M. M. Pimentel, J. Alloys and Compd. 374, 129 (2004).

33. C. H. González, A. J. Q. Cabezas, and M. F. Díaz, Talanta 68, 47 (2005).

34. C. Chung, I. Brenner, and C. You, Spectrochim. Acta, Part B. 64, 849 (2009).

35. F. Ardini, F. Soggia, R. Rugi, and M. Grotti, Anal. Chim. Acta. 678, 18 (2010).

36. F. Ardini, F. Soggia, F. Rugi, R. Udisti, and M. Grotti, J. Anal. At. Spectrom. 25, 1588 (2010).

37. E. C. Vieira, M. Y. Kamogawa, S. J. Lemos, J. A. Nóbrega, and A. R. A. Nogueira, R. Bras. Ci. Solo 29, 547 (2005).

38. F. J. Langmuihr and K. Fringstad, Anal. Chim. Acta 35, 131 (1966).

39. F. Panholzer, Modern techniques digestion, Vienna, 1995.

40. ICP-MS Training, PerkinElmer, Inc., Shelton, CT. USA (1994).

41. K. E. Jarvis, A. L. Gray, R. S. Houk Handbook of Inductively Coupled Plasma Mass Spectrometry, Blackie \& Son Ltd., UK (1991).

42. W. Doherty, Spectrochim. Acta, Part B, 44, 263 (1989).

43. X. Zhang, Y. Yi, Y. Liu, X. Li, J. Liu, Y. Jiang, and Y. Su, Anal. Chim. Acta 555, 57 (2006).

44. X. Zhang, J. Liu, Y. Yi, Y. Liu, X. Li, Y. Su, and P. Lin, Int. J. Mass Spectrom. 260, 57 (2007).
45. S. Zhang, S. Murachi, T. Imasaka, and M. Watanabe, Anal. Chim. Acta 314, 193 (1995).

46. A. J. R. Nardy, F. B. Machado, and M. A. F. Oliveira, Revista Brasileira de Geociências 38, 178 (2008).

47. J. J. R. Fraústo da Silva and M. M. Queimado, Rev. Port. Quim. 15, 29 (1973). 